This is a peer-reviewed, accepted author manuscript of the following article: Kyritsi, K., \& Davis, J. M. (2021). Creativity in primary schools: an analysis of a teacher's attempt to foster childhood creativity within the context of the Scottish Curriculum for Excellence. Improving Schools, 24(1), 47-61. https:// doi.org/10.1177/1365480220968332

\title{
Creativity in primary schools: An analysis of a teacher's attempt to foster child- hood creativity within the context of the Scottish Curriculum for Excellence
}

\author{
Krystallia Kyritsi, The University of Edinburgh, Scotland and John M Davis, University \\ of Strathclyde, Scotland
}

\begin{abstract}
The importance of creativity in education has been increasingly recognised by policy-makers and, as contemporary research argues, the way curricula are organised and implemented impact on children's creativity. Scotland has recently introduced a new curriculum, the 'Curriculum for Excellence' (CfE), but there has yet been no research on how the implementation of the CfE has impacted on childhood creativity. This paper uses qualitative data (field-notes and interview transcripts) - from a case study conducted in one Scottish primary school classroom with 1 teacher and 25 children aged 11-12 - to explore what cultural and structural issues influence childhood creativity. This paper is primarily based on teacher's data and also includes data from seven children. The study found that the CfE can be implemented in both rigid and flexible ways and that structural barriers to creativity emerge when, amongst other causes, cultivation of skills within a tick-box system is perceived as more important than exploration and risk-taking, and when teachers are pressured to evidence the outcomes of their work. This paper concludes that the cultivation of creativity requires schools to build participatory frameworks which leave space for reflection and co-construction and which value diversity, equity and collaboration.
\end{abstract}

Keywords: creativity; childhood; teaching; barriers to creativity; Curriculum for Excellence; Scotland; primary education

\section{Introduction}

The field of creativity has attracted great attention by researchers over time and through different disciplines (Craft, 2005). Despite great interest in the field of creativity, it has been noted that there is a lack of an empirical base in relation to how creativity is promoted and implemented in school environments (Davies et al., 2013), as well as a lack of research in relation to how children's creativity is experienced within the Curriculum for Excellence (CfE) (Cremin and Chappell, 2017).

This paper explores the practical implementation of creativity and identifies cultural and structural parameters that influence childhood creativity in one Scottish primary school classroom. Key questions included in our paper are: What are the possible barriers that may emerge when try- 
ing to implement creativity in practice within a Scottish primary school classroom? And, did the teacher's approach to creativity and the practices adopted for fostering creativity actually enable childhood creativity or simply reproduce the types of performativity that, as research argues, constrain pupils' creativity?

The paper begins by providing a very brief overview of the Scottish educational landscape in terms of policy, curriculum and practice, and highlights the aim for the curriculum to encompass creativity.

Next, the paper highlights the methods used for exploring the main aim and research questions, and discusses the ethical issues of the research. Our findings/discussion sections focus on practical implications for Scottish educational policies, emergent educational practices and pupilteacher relationships. Finally, the conclusion of the paper argues that, when reflecting on how we plan the way forward with regard to creating enabling environments for childhood creativity in Scottish primary education, we need to utilize processes of dialogue and to work towards practicing the $\mathrm{CfE}$ as a child-friendly and participatory curriculum that removes barriers for pupils whilst reducing stress for teachers.

Finally, this paper moves to the innovative conclusion that building child-friendly and participatory frameworks which leave space for reflection and co-construction would be an important step towards enabling the practical implementation of creativity in schools. In doing so it builds on previously innovative discussions in the 'Improving Schools' Journal on the themes of creativity and schooling (Davis, 2013, Jindal-Snape et al., 2013) and school improvement for supporting childhood creativity (Corner, 2012) whilst drawing from international research exploring the important subjects of creativity, curriculum implementation, and supportive structures (Davis, 2013). 


\section{How Scottish Policy Documents support collaboration, flexibility and creativity}

The importance of creativity in education has been increasingly recognised by policy makers and academics in the last 30 years (Wyse, 2013). Definitions of creativity display great variety through different disciplines (e.g. philosophy, psychology, education) (Craft, 2005). This study acknowledges that creativity can be perceived and experienced differently by different people and encourages children to be actively engaged in theorising creativity. The focus of this paper is not to define creativity. Instead, this paper aims to answer questions about how the CfE is interpreted and implemented in practice in a single case example, and also about whether the CfE creates an enabling environment for creativity. Enabling environments have been defined as those that: provide flexible supportive frameworks, are well designed aesthetically, are concerned with promoting equity, value diversity, show respect for people's free thinking, welcome collaboration and eschew rigid rules/ hierarchy (Davis et al., 2011).

The Curriculum for Excellence was launched in 2004 in Scotland for children aged three to eighteen (differing from previous programmes that were targeted at more restricted stages) and formally implemented in 2010 (Priestley and Biesta, 2013). It has been developed as a Scottish Curriculum, distinctive and divergent from other Curricula in the United Kingdom (Humes, 2013). The CfE moved away from the specific and prescriptive content of the previous 5-14 curriculum towards an approach that gave greater freedom to teachers and schools to develop the curriculum (Priestley, 2014). It has been built around four capacities that children and young people are called on to develop (Priestley and Biesta, 2013); that is, the capacities needed to become: successful learners, confident individuals, responsible citizens and effective contributors (Priestley and Biesta, 2013). This feature was aimed at creating more student-centred practices, thus moving a step forward from the previous, content-based curriculum (Priestley and Minty, 2013).

It has been argued that the way curricula are organised and implemented (e.g. employing flexible cross-curricula interdisciplinarity v discrete subjects) impact on children's creativity (Wyse 
and Ferrari, 2015). The CfE has been defined as a curriculum that focuses on 'dialogic pedagogies, active learning and learner autonomy ${ }^{1}$ (Priestley, Biesta and Robinson, 2015, p.114); and that holds the potential to be understood and implemented in more critical ways than other curricula (Ball and Olmedo, 2013). Furthermore, it has been suggested that CfE has opened up new directions towards interdisciplinarity that take us away from rigid divisions and categorisations of subjects towards a more flexible pedagogy (Biesta, Priestley and Robinson, 2015). This shift has led to claims that creativity has been placed at the heart of the $\mathrm{CfE}$ and that the $\mathrm{CfE}$ seeks to shift power to pupils to foster creativity (Cremin and Chappell 2017). Therefore, this paper aims to explore whether the implementation of the $\mathrm{CfE}$ in the case example was enabling to childhood creativity, and to identify possible barriers to the practical implementation of creativity.

\section{Research focus and Methodology}

This paper is a case study, part of a larger ethnographic study that involved four months of fieldwork in one Scottish primary school classroom. The fieldwork was conducted in Little Valley Primary School (a pseudonym), which is located in a suburb of a Scottish city and was chosen in accordance with meeting the broad criteria of being a primary school: a) that implemented the CfE; b) where there was a broad interest in creativity; and c) where ethnographic research could be carried out over an extended amount of time (in keeping with Hammersley and Atkinson, 2007).

The frequency of the visits was 3-4 times per week and 3-6 hours per day for four and a half months. Data were generated from participant observation/informal conversations and one round of semi-structured interviews with twenty-five children (aged eleven to twelve) and one teacher (Juliet). This paper is primarily based on teacher's data, but also uses a limited amount of data from seven children.

\footnotetext{
1 The process of teachers tailoring learning to children's needs (Priestley and Minty, 2013) and
} children taking responsibility for their own learning (Priestley, Biesta and Robinson, 2015). 
This research sought to collect the multiple truths that exist in the social world of one Scottish primary school classroom (Denzin, 1997). From a post-structural standpoint, the representation of participants' different perspectives aimed to make the research process more transparent and, thus, to enhance its rigour by enabling the diverse childhood, ambiguity and polysemy that exist within structures (e.g. a policy context, school, and school classroom) to be better understood (James, Jenks and Prout, 1998). This study does not seek to provide a comprehensive picture of how the CfE promotes creativity for children across Scotland, yet it does provide insight into the interconnected issues that make up the 'whole' of what it is like to experience creative spaces in a single classroom. Therefore, this study synthesises notions of relationships, culture and structure (Davis, 2000) that help the reader to pay attention to the 'whole' (Prout and James, 1997). To do that, this study uses data from interviews from one teacher (Juliet) and three children (Dorothy, Calum and Olivia), and from one excerpt that focuses on a case of collaboration among four children (Arisha, Fatima, Jonathan and Jack). This paper uses data from only seven out of the twentyfive children who participated in this research as suitable cases that will help the reader to build a nuanced picture of what it is like to experience creativity in a primary school classroom, and as a resource from which to draw out our understandings of whether the CfE was enabling to childhood creativity.

Confidentiality and anonymity were important principles which were adopted for this study. The participants were informed that all the data would be stored in a safe place (secure, password protected University computer) and the names of the school, the city and of all the participants were replaced with pseudonyms (Gallagher, 2009). Ethical approval was gained from the author's University ethics committee and informed consent was obtained from the school's head teacher, the classroom teacher, parents and children. Informed consent was a flexible, ongoing and renegotiable process (see Kyritsi, 2019, Kyritsi, 2018) and every effort was made to respect children's right to confidentiality and to guarantee their anonymity. 


\section{Results and Discussion}

\section{Creativity flourishes in environments that provide a balanced approach between freedom and structure}

Many children associated creativity with freedom and opportunities to take the initiative and exert some degree of control over their learning. For example, when asked what creativity was, Dorothy said:

Dorothy: Creativity is the freedom to express yourself in a piece of work. It's ... to put your own spin on things! It's not like a work-sheet answering a question a,b,c. It really means that you get a better understanding of things. And it's better than a plain worksheet. [Interview with Dorothy, 08 June 2015]

Dorothy perceived creativity as a process that gives children the freedom to express themselves and 'put their own spin on things' and viewed freedom, understanding and creativity as interconnected elements forming the creative process.

Paying closer attention to freedom, we note arguments that too much freedom is problematic when seeking to foster creativity; in particular, it was argued that too much individual freedom may raise barriers to people's collaboration; hence, building flexible frameworks containing a balance between freedom and structure is considered necessary for stimulating creativity (Davis et al., 2011). The following examples show how creativity was implemented through balancing freedom and structure.

Dorothy: So we were all told to make a poster advertising Canada and you've got to go anywhere you wanted to go. You could do anything you wanted to do. The only thing you had to do was to have four reasons why you should visit Canada and make it look nice.

Krystallia: So what did you add in your poster?

Dorothy: I put quite a bit of information at the bottom but I tried to keep it 
separate from the big things. I did a big Visit Canada at the top, I did a maple leaf and I did two little tag-lines.

Krystallia: What kind of information did you choose to put there?

Dorothy: I was trying to think what I would like to know if I was gonna

visit Canada. So, obviously there's destinations, food, animals, you know

a bit about the history.

Krystallia: Did you feel creative during doing that?

Dorothy: Yeah.

Krystallia: Why?

Dorothy: Because after you were given those guidelines you were allowed

to create whatever you wanted for the poster and there wasn't a set of rules

about how exactly this should look like, there were guidelines of what

would make it look good. But you could just put your own spin on it and I

really liked that.

Krystallia: Do you feel creative when you have the freedom to choose how you want to do something?

Dorothy: Yeah, because I enjoy being given choice. Because everyone in the class is gonna turn out with a different idea and it means ... you know, you just get to really see everyone's different ideas and ... you do feel creative when you get a certain amount of choice on what you do.

[Interview with Dorothy, 08 June 2015]

Dorothy chose to bring her Canada poster with her to the interview as a prompt that would help her explain her thoughts on what creativity is. The guidelines for the creation of the Canada posters balanced freedom and structure, establishing important conditions for enhancing creativity (JindalSnape et al., 2013). Following Dorothy's reflection on how she structured her poster helps us obtain a clear picture of the way structure and freedom were interwoven (Chappell, 2007), creating a selfreflexive process in which children posed questions on what to include and how best to present information. This process clearly helped children to be actively engaged with knowledge, instead of following instructions and feeling disengaged from the learning process (Craft et al., 2014).

In addition to the above, children were sometimes encouraged to make choices according to their interests, as Calum explains below: 
Krystallia: Do you want to begin by explaining to me what this activity is?

Calum: Well, I brought this activity that we did where we have to make a big ... box and it could be the scare factor or the nice factor and then you will draw a little thing and then at the bottom you would have questions and you would have about six or nine and you've had to find which one, ehm ... for example: I think, blank, is the best footballer because this footballer has been noted as the fastest. So then you look for ... which one is the fastest and ... yeah ... and then the answer is at the back. So that's what we did there.

Krystallia: Is this a game?

Calum: This is like a game but we have to involve maths and stuff like that so ...

Krystallia: Did you choose football?

Calum: Yeah, I chose football players. There is like, there's a game called FIFA and that's quite cool because it has stats and stuff. So I chose that.

Krystallia: So the activity was about making a game?

Calum: Yeah, a game and then you have to answer questions.

Krystallia: And why do you think this is creative?

Calum: I really liked it because it was different because we had to use a key, we had to think of our own things; it was really cool and different.

[Interview with Calum, 04 June 2015]

Calum chose to bring the aforementioned activity to the interview, in order to explain to me what creativity meant to him. As he mentioned, the aim of the activity was to obtain a better understanding of statistics. For this purpose, children were asked to create an individual activity that involved comparisons between fractions. In particular, they were asked to find some characteristics (relevant to the theme of their project) that were expressed as percentages (or, equivalently, as fractions with the denominator 100). This instruction was the same for everyone, but each child had the opportunity to choose the theme of his/her project. For example, some children chose to write about animals, others about sports, music etc. Calum chose to create an activity about famous footballers.

The aforementioned activity chosen by Calum is an example of actively engaging children and involving their interests in the learning process. It has been argued that such initiatives, which connect learning to children's interests, increase their motivation and make learning more meaningful and creative (Craft et al., 2014). Juliet clearly described the aim of the activity but at the same time provided opportunities for children to take the initiative and shape parts of the activity. This 
also links to arguments in progressive pedagogy literature. More specifically, it has been argued that practices based on theories of progressive pedagogy encourage learners to bring their own interests and passions to the learning process, so that learning becomes more than a mere transfer of knowledge (Giroux, 2011). The literature of productive pedagogy adds to that by highlighting that learners become strongly motivated when classroom practices recognise and value their 'background experiences while connecting with their worlds beyond the classroom' (Hayes et al., 2006:37).

This section links to the second research question posed in this paper, as to how enabling the practices adopted for fostering creativity were. A common theme within the thesis dataset (Kyritsi, 2018), which is represented in this section by data from an interview with Dorothy, was the assertion made by children on the need to balance freedom and flexibility with some degree of guidance and structure. Too much freedom was identified by the majority of children as confusing, thus establishing links with other research that points to the need for a balanced approach between structure and freedom (Davis, 2013).

Children valued a balance of freedom and structure, but they were less positive about practices that focused on active learning and learner. The section below shows a contrasting picture, where structural barriers to creativity emerged in the form of rigid practices that reduced children's choice, flexibility, dialogue ${ }^{2}$ and interaction.

\section{Structural practices of differentiation can create barriers to creativity}

Structural approaches to learning such as the way groups were formed and functioned were found to create barriers to creativity. Juliet formed children into different subject ability groups through a process of making them write their name on different sheets of paper. There were three different levels, namely: mild (the easiest level), hot (medium level of difficulty), and extra hot (the highest

\footnotetext{
${ }^{2} \mathrm{~A}$ process of meaning-making from which 'understandings are deepened and judgements coconstructed' (Moss, 2016:11). A process that avoids quantification and objectivity, but instead involves reflection and co-construction within relationships (Moss, 2016).
} 
level for the most difficult activities). Three different sheets of paper (one for each level) were glued behind the door and were visible to everyone. Thus, when children chose a level, they had to add their names to the relevant sheet of paper and this was a form of publicly announcing their level to everyone.

Ability groups were used on a daily basis and Juliet would often remind children to choose the level of their preference for every new activity. Sometimes, she would explain her expectations concerning each level in order to help children choose the right level for themselves. The following two excerpts present children's rationale for choosing their level.

Krystallia: What do you think about the different levels?

Dorothy: I enjoy it because we don't have certain groups in our class, we have quite fluid groups and you can choose for yourself so say...Maths. You might be really, really good at division but not so good at subtraction. And so you can choose the best supporting group to get the right amount of work for you and I think that's very good.

[Interview with Dorothy, 08 June 2015]

In a similar vein, Olivia emphasised the importance of using groups to support their individual progress to the maximum since they worked with children of the same ability level, as described below:

Krystallia: Do you prefer to work with children that are on the same level as you or on a different level?

Olivia: From the same level. I am extra hot which is the hardest work and I like working with other people who are extra hot.

Krystallia: Why?

Olivia: Because we can also help each other and if I was doing it with someone who was say hot then I would have to be helping them a lot and maybe not get to do as much work on my level.

[Interview with Olivia, 10 June 2016] 
In both the above excerpts, children put considerable emphasis on using ability levels for their personal progress and improvement. Dorothy emphasised the connection between individual aims and the collaborative learning potential of the groups when stating she choose 'the best supporting group to get the right amount of work for you'. Olivia utilised hierarchical thinking to justify her preference for working with people from the highest ability level (the level to which she also belonged) because this helped her to do more work, instead of 'wasting' time helping children from a lower level. Thus, the same practice had different meanings to different children and one of those children viewed other children as not worthy of her support.

It has been argued that processes which seek to promote 'high performance' often result in a turn to structured activities and individualistic assessments of 'performance' and away from relationship-based learning (Fielding, 2008). It is suggested that activities that focus strongly on outcomes, measures and attainment are embedded in school programmes, requiring children to be 'individual choosers' (that is, to focus on their individual performance rather than working towards the common good) in order to achieve the best outcomes for themselves (Fielding, 2008:59). Such approaches seem to care more about the 'survival of the fittest' (Ball, 1998) than about the common good, collective empowerment and peer group well-being (Fielding, 2008; Wrigley, 2018). Although teachers utilising such techniques do not seem to intervene that much, as Ball (1998, p.123) portrays, the are still operating 'a form of indirect steering or steering at a distance which replaces intervention and prescription with target-setting, accountability and comparison'. Thus, it can be concluded that the turn towards and focus on individualism and individual progress might also be connected with practices of self-monitoring and self-surveillance - Hence just as a shift to collaborative and creative learning may require a change in parent and teacher cultures (as discussed in the next section) it may also require a change in pupil's hierarchical cultures.

The culture of individualism, which was reinforced by the implementation of the system of 'ability' levels, influenced the performance of children's collaborative relationships and their expe- 
riences of creativity. The following example illustrates a case where children were not included in the group and were discriminated against due to their risk-taking attitude in combination with their perceived 'lower' ability level.

Arisha, Fatima, Jonathan and Jack were working collaboratively on the creation of a group leaflet advertising Canada. The teacher explained the purpose of the activity, gave some guidelines and emphasised the importance of everybody's involvement in group work. During her explanation on how to design this leaflet, Juliet folded a piece of paper in a certain way. Arisha proposed to the group that they should use the teacher's technique to fold up the paper. Since the beginning of these children's collaborative work, Jonathan was trying to fold a piece of paper in different ways. He found one way of folding the paper that he liked a lot and he displayed his idea to the group. The others didn't agree, especially Arisha, who said that this idea was very difficult and confusing. Alice was walking by and Jonathan asked her to have a look at his idea.

Jonathan: Alice, this is MY (emphasising my) idea, but the others go for the teacher's idea!

Arisha: We don't want a confusing idea; we want something basic.

Jack (to Jonathan): When the teacher gives you an idea, the best you can do is to follow their idea!

Arisha (giving directions): Jack, draw a door.

Jack draws a door on the front page.

[Excerpt from fieldnotes, 3 June 2015]

Within this group of four, Jonathan undertook a more autonomous role. He experimented and tried to persuade his team to do something extraordinary. However, his ideas were not accepted by the group and this made him feel disappointed. Arisha belonged to the 'extra hot' level of 'ability'. She was controlling the process and was deciding for the group, something that the other children seemed to accept. Her 'high' academic performance and her stance of acting as an adult in relation to the other members of the group seemed to justify her dominant position in it.

As mentioned in the above excerpt, Arisha proposed using the teacher's technique to fold the paper, and through this action she seemed to construct herself and her position as 'equal' to the teacher and to assume the 'privileged habitus' of an adult (Reay, 1995, p.364). Furthermore, Arisha 
did not want to promote ideas that were not aligned with the teacher's suggestions and, as shown in the above excerpt, she would describe these ideas as difficult and confusing.

Overall, the atmosphere did not seem to encourage risk-taking (Craft, 2003), as children preferred to stick to practices that were familiar to them and were aligned with the teacher's advice, in order for them to finish the task efficiently and with the minimum effort. Children's participation was not a co-constructive and equitable process (Davis and Smith, 2012); some children were able to play an active, decisive, collaborative and creative role, yet their role could often restrain and control other children's level of participation and involvement. Therefore, barriers to childhood creativity were also linked to cultures of exclusion that where created in the classroom as an outcome of individualistic discourses that enabled children's unequal participation based on the performance of their academic 'ability'.

Researchers have highlighted that diversity is very important for creative expression and creativity in general (Glaveanu, Sierra and Tanggaard, 2015), but practices that drive children to individualism raise barriers to that. Based on the above, barriers to childhood creativity are raised for some children when the culture of the classroom focuses on individualism, instead of on building collaborative and flexible practices that focus on equity, critical reflection ${ }^{3}$ and co-construction.

The given examples in this section are linked to research question 2 and have shown a contradictory picture. There were cases where collaborative relationships were fostered within flexible structures, but there were also cases where the creation of collaborative and flexible practices was hindered by the implementation of rigid practices of categorisation and exclusion. It is not our aim to 'blame' Juliet for this outcome, rather by looking closer at Juliet's thoughts and empathetically understanding her perspective we can understand how she formed her actions. The next section discusses Juliet's thoughts on building spaces for enabling creativity within the CfE.

\footnotetext{
${ }^{3}$ A process whereby adults and children actively construct, co-construct and re-construct their understanding(s) of the world(s) (MacNaughton, 2008). Part of the process of meaning-making, 'when understandings are deepened and judgements co-constructed' (Moss, 2016:11).
} 


\section{Teachers have choice on how to implement the Curriculum for Excellence in practice}

An important theme that was mentioned by Juliet is that the CfE is interpreted differently by the leadership and teachers in different schools. The way it is interpreted and implemented can either boost or eliminate barriers to creativity:

Juliet: When I speak to friends who work in other schools in Scotland a lot of them are saying, we have to do it this way. And they are kind of told how to do it. Either from their leadership in the school or from how they have interpreted the CfE. We've got two members of staff moving schools, one out of the country and one within Scotland, and one of them who is within Scotland so has the CfE. They still talked about it as a new curriculum in some schools! And it's not new! Because I've been here for eight years and we've been talking about planning within the CfE for all of those eight years. So I think it's about how your school interprets it. So this one member of staff who is moving within Scotland, she's been told by her new school: they have a grammar book and they are told the pages they are at. They are told that, this is your maths book and do this section. And I just feel that...how is that appropriate for all the children in your class? I just think that's really boring! [Interview with Juliet, 23 June 2015]

Juliet explained that her school had been working towards CfE for 8 years. CfE was introduced in 2006 and formally implemented in 2010 and Juliet viewed its implementation as continuous and ongoing. Juliet possessed a firm view that she and the leadership of 'Little Valley' primary school interpreted the Curriculum in a more flexible way than other schools, building on the idea that, in this school, there was a shared understanding of viewing the curriculum as flexible (Pyhältö et al., 2018).

Juliet points out that the $\mathrm{CfE}$ is not totalising nor always interpreted rigidly, indicating that some teachers might read and implement the policy suggestions in a more flexible way (Ball and Olmedo, 2013). Later, Juliet connected this opportunity to her aim for the pupils to do it their own way: 
Juliet: I love just seeing how independent they are and I just think: I am so proud of you! Because at the start of the year the more were calling up to me: Oh ... 'What do I do?' and 'When do I do this?' You choose what you want to do! How can you learn this? And my class have done just as well as if I had dictated to them: you do this, you do this, you do this, but they are motivated. They like being in school, as much as they can do for eleven-year olds! And they like learning and I think they have a bit more respect because they can do it their own way.

[Interview with Juliet, 23 June 2015]

Juliet was attentive to the possibility to create an environment that fostered children's autonomy. Her views connect with research that argues that the most creative environments are based on mutual respect, trust and enquiry and do not present the teacher as an authoritative figure who holds all the answers, resources and power (Jones and Wyse 2004).

Juliet's aim was to promote a learning atmosphere in which children had choices on how to learn, and where they were active participants in their own learning (Ferrari and Wyse, 2016). In keeping with writing that links creativity to enhanced pupil satisfaction, self-motivation and performance, she placed emphasis on 'how' rather than simply 'what' they learned (Elton-Chalcraft and Mills, 2015).

When contrasting rigidity and flexibility, Juliet reproduces the discourse that suggests that the $\mathrm{CfE}$ is a curriculum which focuses on 'dialogic pedagogies, active learning and learner autonomy' (Priestley et al., 2015:114) - research question 1. However, as we saw in the previous section, cultures of exclusion were created in the classroom as an outcome of individualistic discourses (i.e. the system of 'ability' levels, introduced by Juliet) that led to children's unequal participation. Therefore, Juliet herself did not always live up to her own rhetoric (research question 2). The following sections carefully examine Juliet's actions and aim to shed light on what it was that prevented her from fulfilling her own aspirations concerning creativity. 


\section{The structure of the Curriculum for Excellence: Teacher's rationale for viewing the cur- riculum as chunks}

In the following example, Juliet elaborates on her understanding of the CfE and on the way it was implemented in practice in her classroom.

Krystallia: How do you have the opportunity to give them this choice?

Juliet: I suppose it's my interpretation of the Curriculum, because we are told to give them personalisation and choice. I am telling them today we'll do writing, maths and art. Then when the kids are finished they are doing that finishing off thing... e.g. they write two more sentences or write this, write that. They are getting the opportunity to go back and revisit maths or French...

[Interview with Juliet, 23 June 2015]

Juliet's interpretation of the CfE enabled her to offer children a personalised choice of when and for how long to work on different subject chunks (e.g. writing, maths, etc.) but it did not always offer children an opportunity to work thematically and make creative interconnections between subject chunks (in keeping with Wyse, Hayward, Livingston and Higgins, 2018).

Juliet's positive attitude towards the benefits of personalisation and choice can be linked to the aims of the CfE to promote 'enthusiasm and motivation for learning' (Scottish Executive, 2004, p.12) through creating individualised learning practices (Reeves, 2013). Personalisation is connected with notions of pupil-voice/participation, a democratic child-rights based focus and person-centred learning. It can be a positive thing that helps individuals to have more control over learning spaces and structures by making choices about the style, pace, topic and broad direction of their learning (Reeves, 2013; Fielding, 2008).

Yet, personalisation has been criticised for promoting a neoliberal, managerialist, top-down and modernisation agenda and encouraging educational practices that seek to improve skills, satisfy tick-box criteria and meet economic imperatives rather than foster creative learning (Davis and Smith, 2012; Wrigley, 2006). Here, exploration remains marginalised (Fielding, 2008) because per- 
sonalisation promotes 'learnification of education' (Biesta, 2010), that does not reflect on the purpose of learning by asking questions such as 'what is being learnt and what it is being learnt for' (Priestley et al., 2015, p.10).

CfE does not refer to learning as chunks but calls for learning through themes and interdisciplinarity (Biesta et al., 2015; Priestley et al., 2015). Juliet appears to confuse thematic and chunky approaches and be unaware of research that argues that thematic approaches foster both children's and teachers' creativity (Craft, 2003) and the danger that chunks/discrete subjects might actually eliminate children's creativity 'in discouraging thinking about themes which cross the subject boundaries' (Craft, 2003, p.119).

Overall, Juliet's agenda on personalisation borrowed arguments from children's rights approaches that promote pupil's voice (Reeves, 2013; Fielding, 2008), but also embodied arguments from the managerialist side of personalisation, in the sense that she over-emphasised the individualised nature of learning and did not always engage with writing that looks for synergies between different curriculum areas (Davis and Smith, 2012; Wrigley, 2006). For example, a productive pedagogies approach aims to enable flexible learning environments, where children feel comfortable in sharing their diverse and multiple experiences and taking risks, within a classroom environment that pays attention to the richness of the classroom experience and the interactions between learners' complex identities (see, for example, Lingard, Hayes, Mills and Christie, 2003). In contrast, organising the curriculum through chunks created a rigid structure that did not promote interconnections between different subjects, thus making the conditions for the cultivation of children's creativity more difficult to achieve (research question 1).

The next section discusses how external pressures impacted on the practical implementation of creativity. It describes how parental expectations, and the need for teachers to provide evidence of their work, raised barriers to the promotion of creative practices of teaching and learning. 


\section{Understanding the pressures on the teacher's work: Expectations placed on the teacher to evidence the outcomes of her own work}

Juliet was concerned that parents' perspectives and a need to evidence children's work also created structural constraints in terms of how she might promote flexibility and creativity;

I think the worry of parents and the questioning of our teaching can be a barrier. That's why we are having our class learning records, to show all the other learning. Because some parents come and say: You've not done any maths in their books and it says November! We don't do all our maths in books. We do maths when they are making a poster. All their maths is up, it's the displays, it's the group work. I also think teachers worry about the evidencing of their work. And that's something that we were worried about here, but we've used our class learning record to combat that. And to get children just write in their books, not play the maths game today.

[Interview with Juliet, 23 June 2015]

This suggests that tensions exist between evidencing subject knowledge and promoting flexible and creative learning. Building an engaging and trusting relationship with parents has been described as a tricky and difficult task for teachers (Blomberg and Knight, 2015). Meeting parents' expectations is an extra, and greatly significant responsibility for teachers. As Ball (2003, p.220) argues, teachers have 'a sense of being constantly judged in different ways, by different means, according to different criteria, through different agents and agencies.'

Researchers (Moss, 2016; Fielding, 2008) have argued that professional attempts to build democratic practices of dialogic learning and collective choice are not always highly valued by parents, who can overly focus on the significance of measurable outcomes. This gap between aspiration and reality suggests that a whole community change (the community to include parents) may be required if the $\mathrm{CfE}$ is to substantially alter perceptions and practices. This gap also reminds us that a lack of dialogue on how to enable creative pedagogy results in the de-politicisation of education, creates barriers to effecting change, and fails to enable a sustained change of educational cultures (Moss, 2016; Priestley et al., 2015). 
Juliet's worries about evidencing her work are also highlighted in the literature, where scholars mention that teachers are under pressure to be creative in their teaching, but also to meet universalist externally imposed standards/outcomes and technicist notions of 'what works' rather than ethical, social, political and educational considerations (Ball and Olmedo, 2013; Wrigley, 2011).

Although in Scotland practices of measurement, control and school-level comparisons have not been prevalent lately (Johnson, 2016), there was a recent shift towards increased surveillance of school performances, through the introduction of a programme of standardised testing in Scottish schools (The Scottish Government, 2015).

Juliet argued that this shift had led teachers to avoid spending time on things they consider important and to focus more on what teachers themselves view as meaningless tasks that document teachers' and children's work: as Juliet observed, 'to get children just write in their books, not play the maths game today'. Juliet's concern links to the following questions, mentioned by Ball (2003, p.220): 'Are we doing this because it is important, because we believe in it, because it is worthwhile? Or is it being done ultimately because it will be measured and compared?' In this case, Juliet connects her pressures as a teacher and her lack of opportunity to promote active learning and participation to the pressure to measure and evidence.

Thus, we conclude that the cultivation of creativity in schools needs to be supported by flexible structures in schools (e.g. a shift to thematic and activity-based learning) and cultural change both inside and outside the school (involving teachers and parents) that creates the circumstances where fluid and flexible learning is viewed as valuable and appropriate (research question 1).

\section{Conclusion}

The data presented in this paper demonstrate that important elements of the teacher's approaches that fostered children's creativity included: encouragement of children's autonomy, enabling risk- 
taking, and promotion of children's ownership of learning. Furthermore, this paper argued that barriers to creativity emerged through expectations placed on children to perform well and to focus on their individual progress. In particular, we argued that barriers to creativity emerge when we pay too much attention to individualism, whilst neglecting practices that value diversity, equity and collaboration.

This paper contributes to our understanding of the difficulties encountered when trying to implement creativity in practice. The paper demonstrates that the $\mathrm{CfE}$ can be implemented in both rigid and flexible ways. But it also demonstrates that a teacher's aspiration to provide pupil choice (albeit through hierarchical notions of ability) can also result in children using group work in both integrative and divisive ways.

In addition to the above, this paper argued that parts of the blurred landscape of the creation of environments that foster childhood creativity involve teachers' agendas on personalisation, and their view of the curriculum as consisting of chunks. Personalisation often reflected managerialist arguments focused on ticking boxes, improving specific skills (Wrigley, 2006), and maintaining top-down command and control (Davis and Smith, 2012). This paper argued that structural barriers to children's creativity arose when cultivation of skills within a tick-box system was perceived as more important than exploration and risk-taking.

Structural barriers to creativity were also raised by expectations placed on teachers to evidence the outcomes of their work. This paper demonstrated that teachers felt pressured to work to a rigid, overly evidence-focused 'what works' agenda. These findings are in line with scholarly discussions which mention that teachers are under considerable pressure to meet externally imposed standards (Hayward, 2015) within an educational system that has become excessively technicist (Fielding, 2008) and pays substantial attention to academic outputs (Ball and Olmedo, 2013). In addition, this study observed that structural barriers to creativity and dialogic learning were raised through a knock-on effect of teachers asking children to spend time on meaningless, time-consum- 
ing tasks, because they were fearful of parent perspectives that focus on evidence and hierarchical pupil cultures. Educationalists argue that cultures include teachers' actions and activities (Priestley et al., 2015). We have argued that barriers to creativity emerge from cultures both inside and outside the school and that as well as parent and teacher cultures, pupils' cultures also play a part in individualised learning. Therefore, we seek to conclude this paper by stating that simply providing learning choices outside of dialogue containing notions of inclusion, togetherness and collaborative learning will mean that some children experience the CfE in negative ways when their peers fail to engage with them as equal human beings.

Overall, this paper highlighted the struggles of a teacher who aspired to build creative practices but could not fulfil her aim due to cultural and structural barriers. It is important to mention that this teacher didn't have a fixed identity; barriers were sometimes overcome in this classroom and practices enabling childhood creativity were developed (for a full picture of this ethnography see Kyritsi, 2018). However, although opportunities that promoted children's choice and autonomy did take place at 'Little Valley' Primary School, these attempts were not continuous and consistent. Hence, this paper is able to conclude that, while the CfE includes a vision of more autonomous and flexible practices, the current lack of clarity and direction means that this aim is not always realised. We suggest that it is possible to utilise processes of dialogue in such a way that the problems of the CfE become surmountable by being adapted to become more child-friendly and participatory. Yet, this will only happen if at the same time teachers receive adequate and considered professional development opportunities and enough time to reflect on their practices, to collaboratively work with others to foster joint problem-solving, in order to then make reasonable and thoughtful adjustments to their practices (Ravenscroft et al., 2019). Therefore, two important questions that arise from this paper and that could guide future research are: Are teachers and pupils provided with adequate support to initiate change; and also, could we develop a more strategic approach to better support teachers in building creative classroom environments? 


\section{References}

Ball, S. J. (1998). Big Policies/Small World: An introduction to international perspectives in education policy. Comparative Education, 34, 119-130.

Ball, S. J. (2003). The teacher's soul and the terrors of performativity. Journal of Education Policy, $18,215-228$.

Ball, S. J., \& Olmedo, A. (2013). Care of the self, resistance and subjectivity under neoliberal governmentalities. Critical Studies in Education, 54, 85-96.

Biesta, G., Priestley, M., \& Robinson, S. (2015). The Role of Beliefs in Teacher Agency. Teachers and Teaching: Theory and Practice, 21, 624-640.

Biesta, G. (2010). Good Education in an Age of Measurement: Ethics, Politics, Democracy, Boulder: Paradigm Publishers.

Blomberg, S., \& Knight, B. A. (2015). Investigating Novice Teacher Experiences of the Teaching Dynamics Operating in Selected School Communities in Finland. Improving Schools, 18, 157-170.

Chappell, K. (2007). The Dilemmas of Teaching for Creativity: Insights from Expert Specialist Dance Teachers. Thinking Skills and Creativity, 2, 39-56.

Corner, C. (2012). Into another world: From creativity to creative learning. Improving schools, 15, 116-129.

Craft, A. (2003). The limits to creativity in education: Dilemmas for the educator. British Journal of Educational Studies, 51, 113-127.

Craft, A. (2005). Creativity in schools: tensions and dilemmas, London: Routledge.

Craft, A., Cremin, T., Hay, P. \& Clack, J. (2014). Creative primary schools: developing and maintaining pedagogy for creativity. Ethnography and Education, 9, 16-34.

Cremin, T., \& Chappell, K. (2017). Creative Pedagogic Practice: A Systematic Literature Review. Presentation at ECER 2017, Dublin, paper in preparation. 
Davies, D., Jindal-Snape, D., Collier, C., Digby, R., Hay, P., \& Howe, A. (2013). Creative Learning Environments in Education-A Systematic Literature Review. Thinking Skills and Creativity, $8,80-91$.

Davis, J.M. (2000). Disability Studies as Ethnographic Research and Text: Research Strategies and Roles for Promoting Social Change? Disability \& Society, 15, 191-206.

Davis, J.M. (2013). Supporting creativity, Inclusion and Collaborative Multi-Professional Learning. Improving Schools, 16, 5-20.

Davis, J. M., Bizas, N., Farrier, S., Bruce, A., Petrasch, C., \& Lange, M. (2011). Embedding vision: final report of the CREANOVA project. Edinburgh: Edinburgh University Press. A project funded by the Education, Audiovisual and Culture Executive Agency (EACEA) of the European Commission, Project No. 143725-LLP-1-2008-1-ES-KA1-KA1SCR.

Davis, J. M., \& Smith, M. (2012). Working in multi-professional contexts: a practical guide for professionals in children's services, London: Sage.

Denzin, N. K. (1997). Interpretive ethnography: ethnographic practices for the 21 st century, London: Sage.

Elton-Chalcraft, S., \& Mills, K. (2015). Measuring Challenge, Fun and Sterility on a "Phunometre" Scale: Evaluating Creative Teaching and Learning with Children and Their Student Teachers in the Primary School. Education 3-13, 43, 482-497.

Ferrari, A., \& Wyse, D. (2016). Creativity, Education and Curricula. In: Wyse, D., Hayward, L., \& Pandya, J. (Eds.) The SAGE Handbook of Curriculum, Pedagogy and Assessment. London: Sage.

Fielding, M. (2008). Personalisation, education and the market. Soundings, 56.

Gallagher, M. (2009). Ethics. In: Tisdall, E. K. M., Davis, J. M., \& Gallagher, M. (Eds.) Researching with Children \& Young People. London: Sage.

Giroux, H.A. (2011). On Critical Pedagogy, London: Continuum.

Glaveanu, V. P., Sierra, Z., \& Tanggaard, L. (2015). Widening Our Understanding of Creative Pedagogy: A North-South Dialogue. Education 3-13, 43, 360-370.

Hammersley, M., \& Atkinson, P. (2007). Ethnography: principles in practice, Oxon: Routledge. 
Hayes, D., Mills, M., Christie, P. \& Lingard, B. (2006). Teachers \& Schooling Making a Difference, Australia: Allen \& Unwin.

Hayward, L. (2015). Assessment Is Learning: The Preposition Vanishes. Assessment in Education: Principles, Policy \& Practice, 22, 27-43.

Humes, W. (2013). The Origins and Development of Curriculum for Excellence: Discourse, Politics and Control. In: PRIESTLEY, M. \& BIESTA, G. (eds.) Reinventing the Curriculum: New Trends in Curriculum Policy and Practice London: Bloomsbury.

James, A., Jenks, C., \& Prout, A. (1998). Theorizing childhood, Cambridge: Polity Press in association with Blackwell.

Jindal-Snape, D., Davies, D., Collier, C., Howe, A., Digby, R. \& Hay, P. (2013). The impact of creative learning environments on learners: A systematic literature review. Improving schools, $16,21-31$.

Johnson, S. (2016). National Assessment and Intelligent Accountability. In: Wyse, D. H., Louise \& Pandya, J. (Eds.) The SAGE Handbook of Curriculum, Pedagogy and Assessment. London: Sage.

Jones, R., \& Wyse, D. (2004). Creativity in the Primary Curriculum, London: David Fulton Publishers Ltd.

Kyritsi, K. (2018). Creativity in primary schools: Exploring perspectives on creativity within a Scottish primary school classroom. Edinburgh, UK: University of Edinburgh.

Kyritsi, K. (2019). Doing research with children: Making choices on ethics and methodology that encourage children's participation, Journal of Childhood Studies, 44, 39-50.

Lingard, B., Hayes, D., Mills, M., \& Christie, P. (2003). Leading Learning, Maidenhead: Open University Press.

Moss, P. (2016). Why can't we get beyond quality? Contemporary Issues in Early Childhood, 17, 815.

Prout, A. \& James, A. (1997). A new Paradigm for the Sociology of Childhood? Provenance, Promise and Problems. James, A. \& Prout, A. (eds.) Constructing and Reconstructing Childhood. Contemporary Issues In The Sociological Study of Childhood. London: Falmer Press. 
Pyhältö, K., Pietarinen, J., \& Soini, T. (2018). Dynamic and shared sense-making in large-scale curriculum reform in school districts. The Curriculum Journal, 29(2), 181-200.

Priestley, M. (2014). Curriculum regulation in Scotland: A wolf in sheep's clothing is still a wolf. European Journal of Curriculum Studies, 1, 61-68.

Priestley, M., Biesta, G., \& Robinson, S. (2015). Teacher Agency: An Ecological Approach, London: Bloomsbury.

Priestley, M. \& Biesta, G. (2013) Introduction: The New Curriculum. In: Priestley, M. \& Biesta, G. (eds.) Reinventing the Curriculum: New Trends in Curriculum Policy and Practice. London: Bloomsbury.

Priestley, M., \& Minty, S. (2013). Curriculum for Excellence: ‘A brilliant idea, but...'. Scottish Educational Review, 45(1), 39-52.

Ravenscroft, J., Davis, J., Bilgin, M., \& Wazni, K. (2019). Factors that influence elementary school teachers' attitudes towards inclusion of visually impaired children in Turkey. Disability \& Society, 34(4), 629-656.

Reay, D. (1995). 'They Employ Cleaners to Do that': habitus in the primary classroom. British Journal of Sociology of Education, 16, 353-371.

Reeves, J. (2013). The Successful Learner: A Progressive or an Oppressive Concept? In: Priestley, M., \& Biesta, G. (Eds.) Reinventing the Curriculum: New Trends in Curriculum Policy and Practice. London: Bloomsbury.

Scottish Executive. (2004). A curriculum for Excellence. The curriculum review group. Edinburgh.

The Scottish Government. (2015). Creating a Smarter Scotland: A Draft National Improvement Framework for Scottish Education. Edinburgh.

Wrigley, T. (2006). Another school is possible, London: Bookmarks Publications.

Wrigley, T. (2011). Paradigms of School Change. Management in Education, 25, 62-66.

Wrigley, T. (2018). 'Knowledge', curriculum and social justice. The Curriculum Journal, 29(1), 4-24.

Wyse, D. (2013). Creativity. In: Wyse, D., Baumfield, V. M., Egan, D., Gallagher, C., Hayward, L., Hulme, M., Leitch, R., Livingston, K., \& Menter, I. (Eds.) Creating the Curriculum. Oxon: Routledge. 
Wyse, D., \& Ferrari, A. (2015). Creativity and education: comparing the national curricula of the states of the European Union and the United Kingdom. British Educational Research Journal, 41(1), 30-47.

Wyse, D., Hayward, L., Livingston, K., \& Higgins, S. (2018). Traditional school subjects versus progressive pedagogy. The Curriculum Journal, 29(3), 295-297. 